\title{
PROSES KERJA KOMPUTER \\ YANG DAPAT MENGOPTIMALKAN \\ HASIL KOMUNIKASI VISUAL SECARA EFISIEN
}

\author{
Andreas James Darmawan \\ Jurusan Desain Komunikasi Visual, Fakultas Komunikasi dan Multimedia, \\ Bina Nusantara University, Jln. K.H. Syahdan No. 9, Palmerah, Jakarta Barat 11480 \\ james.dar@gmail.com
}

\begin{abstract}
To be able to work optimally and efficiently by computer, in making a visual communication, we need to understand the three kinds of process/ how to work a computer. There are three bases logic how computer works, such as text, pixel, and vector. Each made with different methods of logic, as a result of efforts to meet the needs of creators of computer communication. So after the third understands the workings of TSB, the ease and optimization in making a visual communication can be achieved.
\end{abstract}

Keywords: text, pixel, vector, optimal and efficient visual communication

\begin{abstract}
ABSTRAK
Untuk dapat bekerja optimal dan efisien dengan komputer, dalam membuat sebuah komunikasi visual, kita perlu mengerti tiga macam proses / cara bekerja sebuah komputer. Ada tiga basis logika kerja komputer, antara lain teks, pixel, dan vektor. Masing-masing diciptakan dengan metode logika yang berbeda, sebagai hasil usaha pencipta komputer untuk memenuhi kebutuhan komunikasi. Sehingga setelah mengerti ketiga cara kerja tersebut, kemudahan, dan optimalisasi dalam membuat sebuah komunikasi visual dapat dicapai.
\end{abstract}

Kata kunci: teks, pixel, vektor, komunikasi visual optimal dan efisien 


\section{PENDAHULUAN}

Komputer memudahkan untuk melakukan banyak hal, tetapi sebagian besar yang membuatnya lebih mudah dilakukan, tidak perlu dilakukan (Andy Rooney, 2009).

"Computers make it easier to do a lot of things, but most of the things they make it easier to do don't need to be done."

Inilah yang terjadi di masa sekarang; dengan adanya teknologi komputer, banyak hal yang telah mempermudah proses kerja kita. Namun, ternyata belum semua itu optimal dan efisien. Demikian juga dalam proses membuat sebuah komunikasi visual, semua peranan komputer tersebut akan lebih optimal dan efisien, apabila kita mengerti logika proses dan metode kerja komputer dalam membantu kita membuat sebuah komunikasi visual secara optimal dan efisien. Yang menjadi latar belakang penelitian ini adalah minimnya pengetahuan, baik kalayak umum maupun khusus, tentang 3 basis logika proses kerja komputer dalam membuat sebuah komunikasi visual. Apabila jurnal ini terpublikasi, maka pengetahuan akan logika ini akan tersosialisasi sehingga dapat memberikan pengertian dan pedoman yang optimal serta efisien dalam membuat sebuah komunikasi visual dengan menggunakan komputer.

Kondisi minimnya pengetahuan tentang proses kerja komputer tersebut menjadi sebuah masalah yang cukup signifikan karena kesalahan proses pembuatan sebuah komunikasi visual yang tidak terbagi dalam 3 format di atas, membuat hasil yang dibuat menjadi tidak dapat dipakai ketika sebuah komunikasi visual tersebut masuk ke dalam proses selanjutnya, yaitu proses cetak. Sebab dalam proses cetak, sebuah hasil komunikasi visual yang tidak tepat dapat seringkali membuat hasil cetak tidak sesuai dengan yang diinginkan. Hasil yang menyimpang itu sering terjadi pada pecahnya kualitas gambar sehingga komunikasi visual menjadi blur atau tidak fokus.

Untuk itu, tujuan penelitian ini adalah untuk memberikan pola pemikiran yang tepat dalam membuat sebuah proses komunikasi visual dengan komputer sehingga menjadi optimal dan efisien. Yang dimaksud dengan pola pemikiran tersebut adalah pola pemikiran yang terbagi menjadi 3 bagian, yaitu teks, pixel, dan vektor. Sehingga setelah membaca jurnal ini, diharapkan perancang komunikasi sejak awal proses pembuatan komunikasi visual, telah terpikir untuk memilah ketiga proses logika kerja tersebut secara tepat.

\section{METODE PENELITIAN}

Metode penelitian yang dilakukan dalam membuat pembahasan jurnal ini antara lain metode studi pustaka guna mendapatkan landasan teori, metode ekperimen digital, dan metode observasi hasil pencetakkan komunikasi visual. Metode studi pustaka yang dilakukan penulis dengan menggabungkan pustaka yang menjelaskan berbagai proses bekerja sebuah komputer. Setelah mendapatkan tiga formula basis logika yang mendasar dan saling melengkapi dari proses logika kerja komputer, penulis melanjutkan proses ekperimen secara komputerisasi atau digital.

Untuk metode ekperimen digital, langkah yang dilakukan penulis adalah membuat sebuah komunikasi visual yang sama. Namun penulis sengaja membagi format sebuah komunikasi visual tersebut kedalam berbagai kemungkinan perpaduan proses logika kerja komputer. Dari komunikasi visual yang dihasilkan, penulis melakukan observasi dan membuat perumusan. Sehingga lahirlah sebuah gagasan yang merupakan kesimpulan dari penggabungan pola kerja yang optimal dan efisien. Setelah kedua metode tersebut dilakukan, sebagai langkah terakhir dan yang menjadi langkah finalisasi keberhasilan tiga proses logika kerja komputer, penulis melakukan observasi hasil proses cetak dari komunikasi visual yang dibuat. 


\section{HASIL DAN PEMBAHASAN}

Agar dapat mengikuti pembahasan jurnal ini, sebelumnya perlu ada penjelasan dari setiap ketiga proses logika kerja komputer. Berikut ini ada pula pembahasan tentang kelebihan dan kekurangan setiap proses, software yang dapat digunakan untuk memprosesnya, serta format penamaan file dari setiap proses logika kerja komputer ini. Proses logika kerja komputer dengan basis teks merupakan bahasa dasar sebuah komputer untuk mengerti perintah atau task yang diberikan pengguna terhadapnya. Bisa dikatakan juga bahwa proses logika kerja komputer basis teks ini adalah sebuah code dasar yang memiliki pengertian yang sama antara manusia dengan komputer dalam menerjemahkan bahasa tersebut.

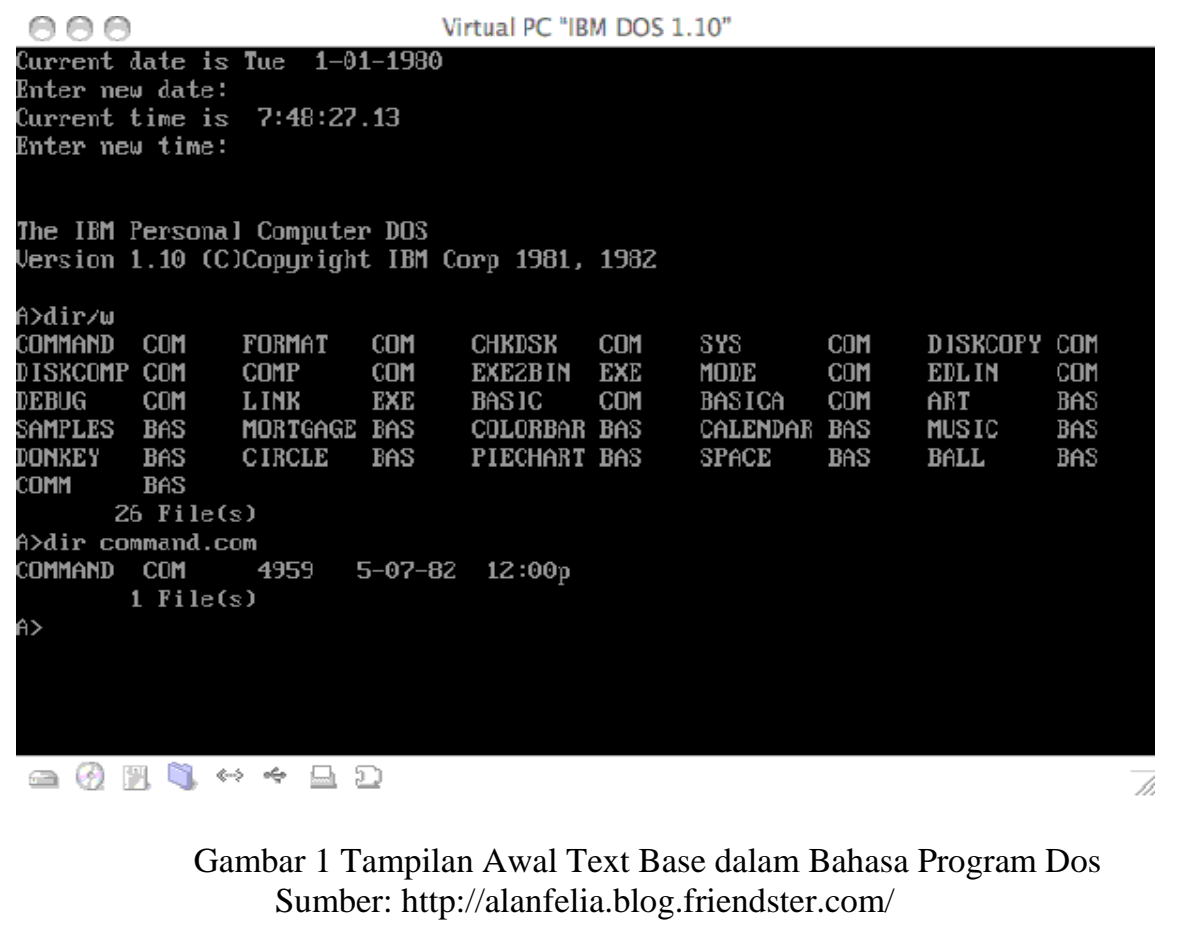

Kelebihan proses logika kerja komputer basis teks adalah dapat memenuhi kebutuhan komunikasi secara mendasar, termasuk dapat dijadikan sebuah perintah untuk menjalankan program dalam komputer itu sendiri yang bersifat variable atau logika if dan else. Sedangkan kekurangan proses logika kerja komputer basis teks adalah keterbatasan dalam grid dan layout. Hal ini membuat basis teks menemukan kesulitan tersendiri dalam pembuatannya, karena hasil komunikasi visual yang tercipta melalui basis teks ini, menjadi terbatas dan terkesan bertentangan terhadap pemenuhan kebutuhan dunia seni yang dituntut menciptakan karya tanpa batas.

Software yang dapat digunakan untuk memprosesnya basis teks ini, antara lain : Microsoft Office dan Adobe Dreamweaver. Sedangkan format sebuah file basis teks antara lain : txt, rtf, doc, xls, ppt, dan html. Proses logika kerja komputer dengan basis pixel merupakan inovasi brilian yang memanfaatkan kemampuan setiap titik pixel untuk menghasilkan warna. Sehingga apabila gabungan titik-titik pixel tersebut dilihat secara menyeluruh, maka gabungan warna-warni tersebut dapat menghasilkan sebuah gambar yang memiliki kualitas foto. 


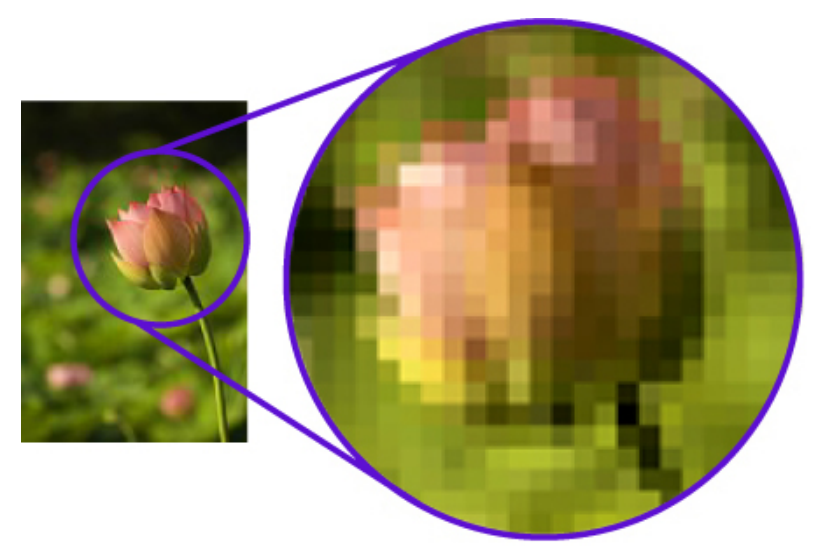

Gambar 2 Pixel yang Mampu Menampilkan Multigradasi Karena Sistem Pembuatannya Menggunakan Setiap Peran Titik Pixel Monitor Sumber: http://vector-conversions.com/vectorizing/raster_vs_vector.html

Kelebihan proses logika kerja komputer basis pixel adalah memanfaatkan setiap pixel yang ada pada tampilan monitor sehingga sistem proses kerja ini dapat memungkinkan komputer untuk menampilkan sebuah gambar fotografik yang memiliki multi gradasi. Sedangkan kekurangan proses logika kerja komputer basis pixel adalah apabila gambar tipe pixel diperbesar melebihi kapasitasnya, maka gambar tersebut akan menjadi terlihat batas gradasinya, kejadian ini sering disebut dengan istilah gambar yang pecah. Hal ini dapat terjadi karena sebuah pixel memiliki kapasitas ukuran.

Software yang dapat digunakan untuk memprosesnya basis pixel ini, antara lain Corel Photo Paint dan Adobe Photoshop. Sedangkan format sebuah file basis teks antara lain bmp, jpg, gif,png, tif, tga, dan psd. Proses logika kerja komputer dengan basis vektor menggunakan titik pixel menjadi sebuah koordinat. Setiap titik koordinat memiliki tugas sebagai terminal penyambung garis antar titik koordinat yang lain. Sehingga dengan sistem ini memungkinkan terbentuknya sebuah kurva atau bidang, apabila terjadi garis penggabungan titik awal koordinat menyatu dengan titik akhir koordinat. Kurva tersebut dapat diisi dengan blok warna, dan dapat pula diisi dengan gradasi-gradasi yang simpel.

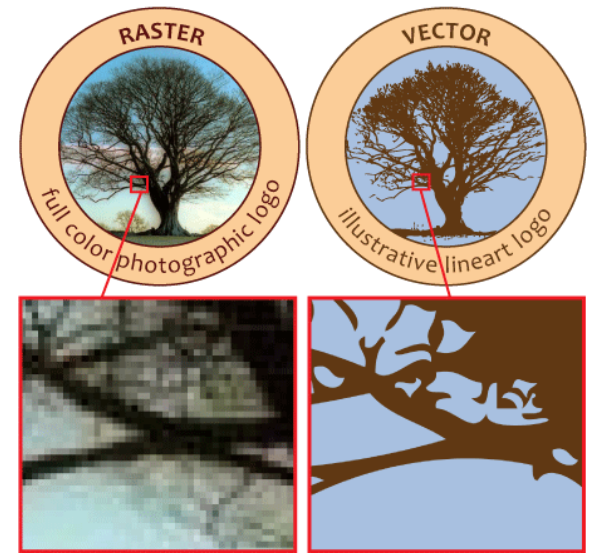

Gambar 3 Perbandingan Gambar Basis Pixel yang Memiliki Kualitas Fotografik, Namun Dapat Pecah Apabila Diperbesar, dan Vektor yang Memiliki Sistem Penggambaran Koordinat sehingga Berkualitas Grafik, Namun Tidak Dapat Pecah Sumber: http://vector-conversions.com/vectorizing/raster_vs_vector.html 
Kelebihan proses logika kerja komputer dengan basis vektor adalah : dengan menggunakan koordinat titik-titik yang dihubungkan dengan garis, maka proses ini tidak akan menemukan masalah penurunan kualitas gambar ketika terjadi pembesaran ukuran gambar sampai sebesar apapun. Sedangkan kekurangan proses logika kerja komputer dengan basis vektor merupakan namun, karena proses ini hanya merupakan kurva yang dapat diisi dengan blok warna dan gradasi yang simpel, jenis gambar vector sangat sulit mencapai qualitas gabar fotografik yang memiliki multi gradasi. Biasanya gambar vector ini disebut memiliki kualitas gambar grafik (bukan fotografik).

Software yang dapat digunakan untuk memprosesnya basis vektor ini, antara lain : Corel Draw dan Adobe Illustrator. Sedangkan format sebuah file basis teks antara lain : eps, cdr, fh, dan ai. Dari hasil observasi terutama dilihat dari kelebihan dan kekurangan masing-masing basis proses logika kerja komputer, makan dapat disimpulkan bahwa kolaborasi ketiga proses logika kerja komputer tersebut sangat diperlukan dalam memenuhi kebutuhan pembuatan sebuah komunikasi visual yang optimal dan efisien. Contoh konkret untuk melihat gabungan ketiga basis proses logika kerja komputer dapat sering kali terjadi, misalnya dalam sebuah iklan majalah. Sebuah iklan yang baik adalah iklan yang dapat menjual produk atau jasanya.

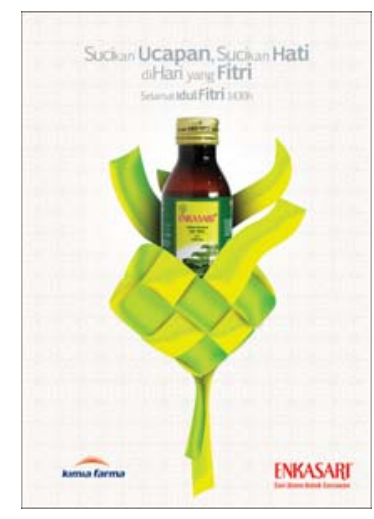

Gambar 4 Contoh Bahan Pembahasan: Iklan Majalah Sebuah Produk Sumber: Karya Komunikasi Visual Penulis

Peranan komunikasi verbal berupa teks tentunya sangat diperlukan didalam sebuah iklan majalah. Teks tersebut dapat berdiri sebagai headline atau subheadline, sampai menjadi bodycopy sebuah iklan. Disinilah letak peranan proses logika kerja komputer berbasis teks. Dengan basis ini, proses pembuatan sebuah iklan agar dengan mudah direvisi apabila memerlukan perubahan teks, baik secara konten maupun style visual teks, sebab basis ini memang bersifat aktif terhadap perubahan.

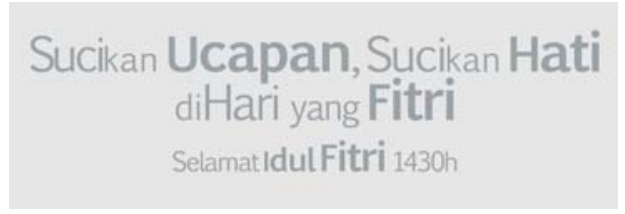

Gambar 5 Basis Teks yang Terkandung dengan Style Visual yang Menarik Sumber: Karya Komunikasi Visual Penulis

Sedangkan untuk menjelaskan detail tentang produk yang dijualnya, iklan majalah sering kali memasukan unsur foto. Kualitas gambar fotografik memang unggul dalam memberikan imaji realistik tentang produk yang diiklankan. Di sini peranan proses logika kerja pixel berperan. Tanpa proses 
berbasis pixel, secara digital, komputer tidak akan mampu memberikan gambar yang memenuhi rasa ingin tahu konsumen dalam mencari produk tersebut. Hal ini juga dapat mengarahkan konsumen untuk membeli brand produk yang benar sesuai iklan.

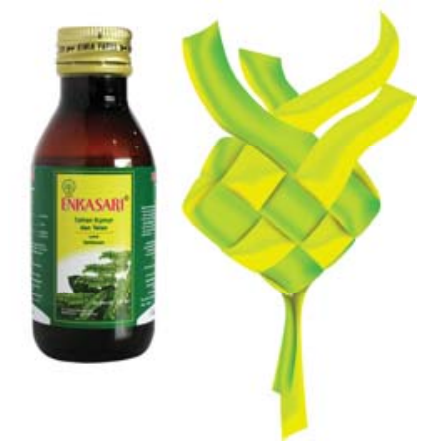

Gambar 6 Basis Pixel yang Berkualitas Fotografik

Sehingga Cocok untuk Memperlihatkan Bentuk Produk yang Ingin Diiklankan

Sumber: Karya Komunikasi Visual Penulis

Jangan lupa bahwa sebuah iklan memerlukan logo brand didalamnya, logo brand inilah yang lebih menguntungkan apabila dimasukkan dalam format gambar grafik berbasis vektor sehingga memperoleh gambar yang tajam dan tidak pecah.

\section{kımıa farma

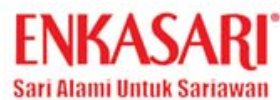

Gambar 7 Basis Vektor yang Digunakan untuk Sebuah Logo

Agar Memiliki Kualitas yang Tajam

Sumber: Karya Komunikasi Visual Penulis

Kasus lain dapat kita lihat dalam sebuah desain packaging atau kemasan. Sebuah kemasan sekali lagi memerlukan ketiga unsur di atas. Kolaborasi ketiga proses logika kerja komputer perlu bersatu guna membarikan sajian kemasan yang terbaik. Perlu diingat bahwa sebuah kemasan harus dapat bersaing, ketika kemasan tersebut diletakan dalam display dalam sebuah supermarket. Tentunya banyak kompetitor produk sejenis yang akan berdiri pula pada display tersebut, untuk itu selain proteksi, kemasan juga memiliki tanggung jawab untuk dapat menjual dirinya dari antara kompetitor.

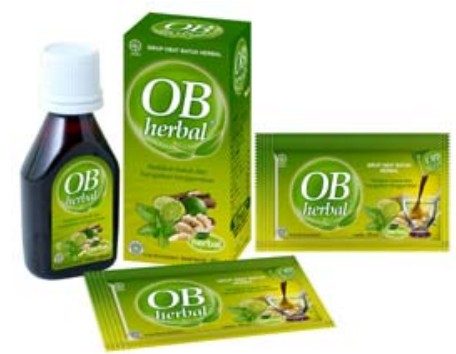

Gambar 8 Sebuah Desain Packaging Obat Batuk Sumber: Karya Komunikasi Visual Penulis 
Berikut pembahasan kemasan dari sebuah produk obat batuk. Sebagaimana hasilnya, pembahasan kemasan diambil dari kemasan box saja sebagai perwakilan keseluruhan sistem komunikasi visual kemasan.

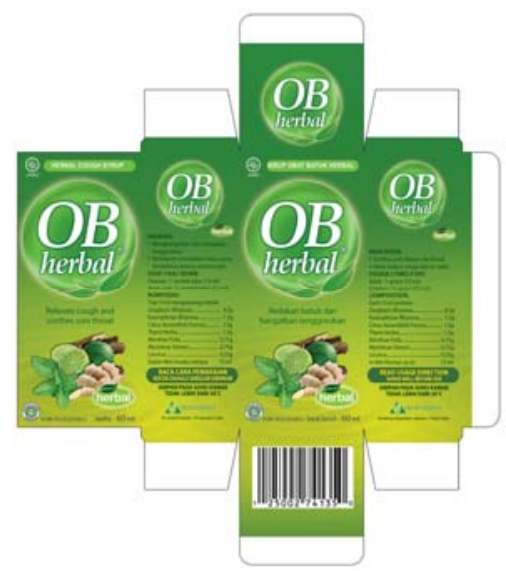

Gambar 9 Sebuah Bentangan Desain Box Packaging Obat Batuk Sumber: Karya Komunikasi Visual Penulis

Basis teks diperlukan untuk memberikan semua keterangan verbal, mulai dari varian rasa, mandatori produk, sampai pada keterangan BPOM RI. Peranan basis teks disini juga memiliki beberapa dinamika stlye visual, baik secara single text maupun text box. Untuk kemasan, peranan text box sangat terasa, hal ini terjadi karena sebuah komunikasi visual kemasan memiliki limitasi ukuran. Sehingga pengaturan yang optimal diperlukan untuk membuat keterangan kemasan berbasis teks efisien dalam pembuatannya.

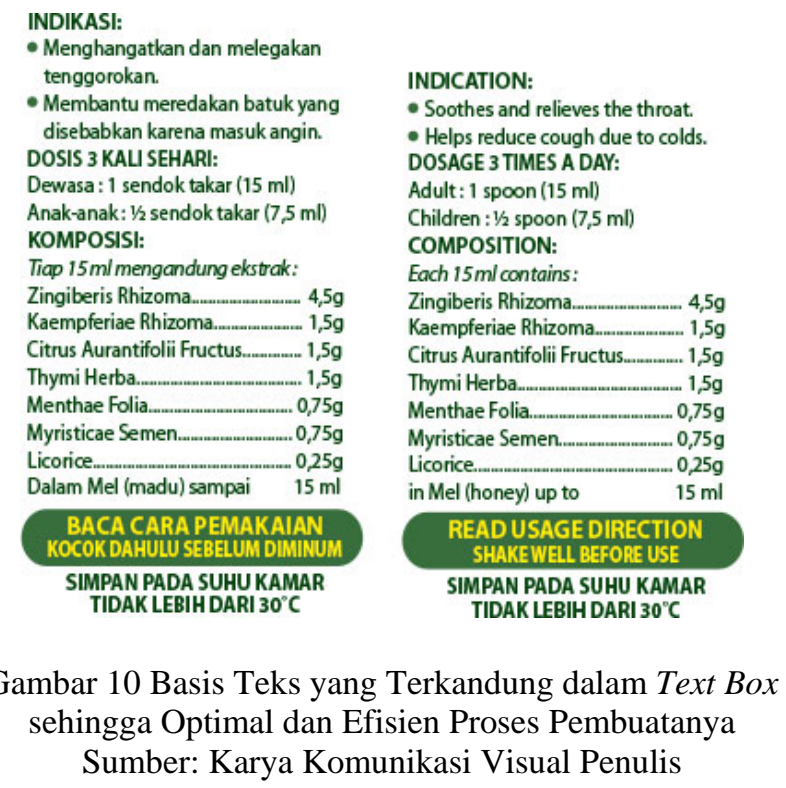

Untuk unsur basis pixel, juga peranannya sangat diperlukan untuk memberikan foto realistik yang dapat memberikan imaji yang cantik, sehingga mengundang kepercayaan konsumen terhadap produk yang terkandung dalam kemasan tersebut. Peranan basis pixel ini yang menjadi faktor utama dalam menentukan daya tarik kemasan. 


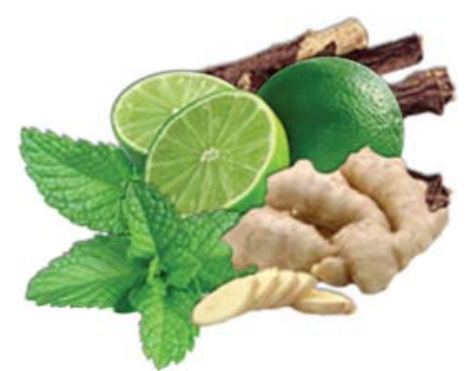

Gambar 11 Basis Pixel dalam Kemasan, Sangat Berperan dalam Tampilan Ingredients, Product Shot, dan Beauty Shot Sumber: Karya komunikasi Visual Penulis

Demikian pula logo dan ikon-ikon tambahan, mereka adalah faktor yang harus dalam sebuah kemasaan. Terutama logo brand itu sendiri, harus menjelaskan bahwa produk ini beda dengan yang lain. Sebab terkadang dalam brand yang sama, juga masih memiliki varian yang sama. Disinilah peranan basis vektor, sebab basis vektor dapat membuat kualitas dan macam ukuran pemakaian yang lebih luas.
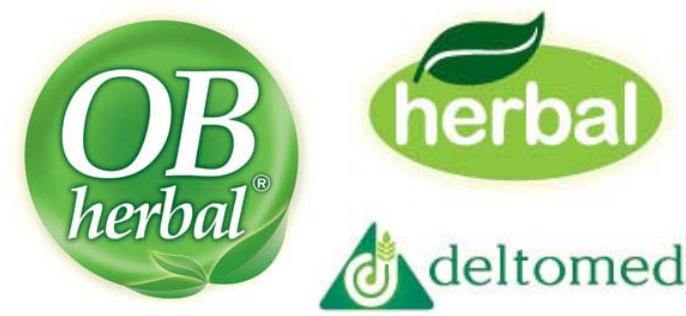

Gambar 12 Basis Vektor dalam Kemasan,

Sangat Berperan dalam Logo dan Ikon

Sumber: Karya komunikasi Visual Penulis

Sesungguhnya ketiga unsur tersebut harus berkolaborasi sehingga dapat menghasilkan sebuah komunikasi visual yang optimal dan efisien. Basis teks biasa digunakan dalam pembuatan media komunikasi verbal seperti membuat surat, pengumuman, dan apapun yang memiliki tulisan text di dalamnya. Untuk basis vektor, banyak digunakan berdasarkan kelebihannya yang tidak dapat pecah, text base biasa dipakai untuk pembuatan sebuah gambar logo, icon, atau bidang kurva grafik sederhana. Sedangkan basis pixel tentunya biasa dipakai untuk memasukan unsur foto kedalamnya, apakah foto tersebut berdiri sendiri sebagai sebuah karya komunikasi, atau dapat pula digabungkan dengan text atau komukasi verbal yang menjadi sebuah layout.

\section{SIMPULAN}

Dengan mengetahui, memahami, dan mengaplikasikan ketiga proses logika kerja sebuah komputer, yaitu teks, pixel, dan vektor, dalam membuat sebuah komunikasi visual, maka kita akan peroleh akan menjadi sebuah pencapaian yang optimal dan efisien. Pencapaian di atas dapat dikatakan optimal karena ditinjau dari hasil komunikasi visual yang dapat diproses dengan baik dalam proses cetak sebagai bentuk proses selanjutnya. Dalam hal ini, apabila penempatan proses logika kerja sudah tepat, penyimpangan hasil cetak akan berkurang secara signifikan. Sedangkan pencapaian di atas dapat dikatakan efisien karena ditinjau dari proses dalam membuat komunikasi visual tersebut. Dengan pola pemikiran yang terbagi secara tepat, perancang komunikasi sejak awal proses pembuatan komunikasi 
visual, telah terpikir untuk memilah ketiga proses logika kerja tersebut secara tepat. Segmentasi pola pemikiran ketiga proses logika kerja sebuah komputer. Dalam membuat sebuah komunikasi visual tersebut, harus berdasarkan pemahaman mendasar dari segi kelebihan dan kekurangan masing-masing basis proses logika kerja. Hal ini akan menjadikan perancang komunikasi bijaksana dalam memilih basis yang paling tepat dalam menyelesaikan sebuah solusi visual yang komunikatif.

\section{DAFTAR PUSTAKA}

Foley, J.D., van Dam, A., Feiner, S.K., and Hughes, J.F. (1997). Computer graphics principles and practice, $2^{\text {nd }}$ ed., Boston, USA: Addison Wesley.

Gordon, B., and Gordon, M. (2002). The complete guide to digital graphic design, $1^{\text {st }}$ ed., London, France: Thames \& Hudson.

Leeuw, B.D. (1997). Digital cinematography, $1^{\text {st }}$ ed., London, France: AP Professional.

Roojen, P.V. (2004). Web design index 5, Amsterdam, Netherlands: The Pepin Press - Agile Rabbit Editions.

Xiang, Z., and Plastock, R. (2001). Computer graphics, $2^{\text {nd }}$ ed., Singapore: McGraw-Hill. 